\title{
Fine and Coarse Aerosol at Rio de Janeiro prior to the Olympic Games: Chemical Composition and Source Apportionment
}

\author{
Maria Luiza D. P. Godoy, ${ }^{a}$ Ana C. Almeida,${ }^{b}$ Gisele B. Tonietto ${ }^{b}$ and \\ José Marcus Godoy*,b \\ aInstituto de Radioproteção e Dosimetria, Avenida Salvador Allende s/n, \\ 22780-160 Jacarepaguá-RJ, Brazil \\ ${ }^{b}$ Departamento de Química, Pontifícia Universidade Católica do Rio de Janeiro, \\ Rua Marquês de São Vicente, 225, 22451-900 Gávea-RJ, Brazil
}

\begin{abstract}
During the period from June 2012 to June 2013, the concentrations and chemical composition of $\mathrm{PM}_{2.5}$ and $\mathrm{PM}_{2.5-10}$ (particulate matter with a diameter of $2.5 \mu \mathrm{m}$ or less and between 2.5 and $10 \mu \mathrm{m}$, respectively) were monitored at four sampling points in the Rio de Janeiro metropolitan area, and two of the points were in close proximity to the 2016 Olympic Games facilities with a total of 122 samples at each sampling point. At all four sampling stations, the annual mean value of $\mathrm{PM}_{10}$ was above the World Health Organization (WHO) air quality guideline, although frequent violations of the $24 \mathrm{~h}$ guideline were observed at only two of the points, Duque de Caxias and Taquara. On the other hand, $\mathrm{PM}_{2.5}$ concentrations at the four sampling points met both the annual and $24 \mathrm{~h}$ WHO $\mathrm{PM}_{2.5}$ air quality guidelines. The vehicular contribution to $\mathrm{PM}_{2.5}$ ranged from 48 to $70 \%$, with a mean value of $59 \pm 9 \%$. Considering that the Brazilian market already has fuel quality that is comparable to international standards (gasoline S50 and diesel S10), further air quality improvements are expected with investments in a public transport network, urban mobility programs and fleet renewal, which are considered a legacy of the 2016 Olympic Games.
\end{abstract}

Keywords: air pollution, aerosol, 2016 Olympic Games, Rio de Janeiro, source apportionment

\section{Introduction}

After the 2008 Beijing Olympic Games, several restrictions to vehicular traffic and industrial activity were imposed due to poor air quality. Regional air quality was one of the local organization's priorities and a compromise with the International Olympic Committee, as fine particulates and ozone were two parameters of concern due to their relationship with respiratory diseases. ${ }^{1-5}$ Several studies have shown that these restrictions had a limited effect on air quality during the 2008 Olympic Games because other factors, such as weather conditions, also contribute to air quality. ${ }^{1-3}$ In particular, the particulate matter with a diameter of $2.5 \mu \mathrm{m}$ or less $\left(\mathrm{PM}_{2.5}\right)$ levels exceeded the World Health Organization (WHO) $24 \mathrm{~h}$ guideline $\mathrm{e}^{6}$ during the entire period of the 2008 Olympic Games. ${ }^{1,2}$

In contrast to Beijing, Godoy et al. ${ }^{7}$ demonstrated that for $\mathrm{PM}_{2.5}$, the air quality measurements conducted close to future Olympic facilities met the WHO annual and $24 \mathrm{~h}$ guideline. Since this study, this region has dealt

*e-mail: jmgodoy@puc-rio.br with substantial changes in new roads and buildings, which have caused a dramatic increase in the number of vehicles traveling through the area over the last few years. The present work was developed at two sampling stations that were located close to the 2016 Olympic Games facilities, and the results demonstrated that levels remain in agreement with the $\mathrm{PM}_{2.5}$ WHO guidelines. ${ }^{6}$ However, the impact of the ongoing infrastructure interventions was clearly observed on the particulate matter with a diameter between 2.5 and $10 \mu \mathrm{m}\left(\mathrm{PM}_{2.5-10}\right)$ fraction.

In addition to the two sampling stations, two other sampling locations were included in the present study: one representing a residential neighborhood with heavy vehicular traffic and the other representing one of the most industrialized regions neighboring the city of Rio de Janeiro.

\section{Experimental}

Ambient aerosol sampling was performed simultaneously at 4 sites distributed in different locations of the Rio de Janeiro metropolitan area (Figure 1) using 


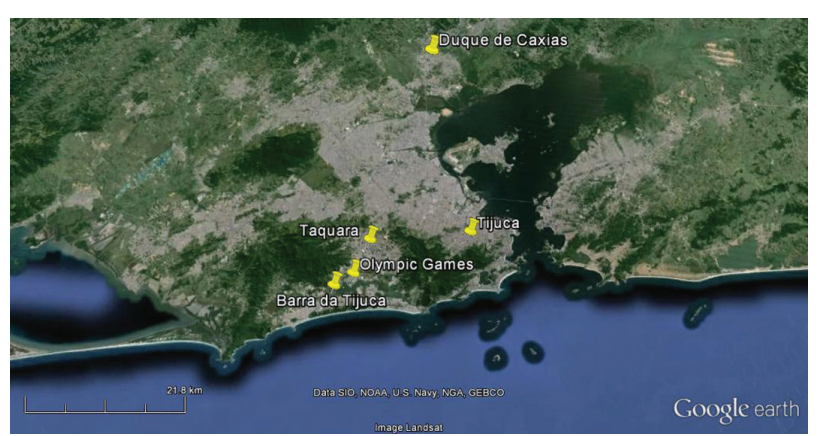

Figure 1. Locations of the four sampling sites and the 2016 Olympic Games region.

a one-in-three day schedule from June 2012 to June 2013 and provided a total of 122 sampling days.

The aerosol was collected at a flow rate of $17 \mathrm{~L} \mathrm{~min}^{-1}$. The sample volume was obtained with gas volume meters, and they were individually calibrated with the Gilibrator (Gilian Instruments Corporation), which is a primary standard airflow calibrator. At each site, two integrated $24 \mathrm{~h}$ ambient aerosol samplers were mounted.

The first aerosol sampling system was used to collect fine and coarse aerosol particles to determine aerosol mass, black carbon (BC) and elemental concentrations. The aerosol was collected in two Nuclepore ${ }^{\circledR}$ filters on stacked filter units (SFU) from NILU (Norwegian Institute for Air Research) after passing through an Environmental Protection Agency (EPA) design PM P $_{10}$ inlet from BGI Mesalabs (http:// bgi.mesalabs.com/accessories), which removes aerosol particles greater than $10 \mu \mathrm{m}$. The SFU collects coarse mode particles $(2.5<$ particle diameter $(\mathrm{dp})<10 \mu \mathrm{m})$ on a $47 \mathrm{~mm}$ diameter, $8 \mu \mathrm{m}$ pore size Nuclepore filter while a $0.4 \mu \mathrm{m}$ pore size Nuclepore filter collects the fine mode particles $(\mathrm{dp}<2.5 \mu \mathrm{m})$. The sum of both size fractions provides $\mathrm{PM}_{10}$ that refers to aerosol particles smaller than $10 \mu \mathrm{m}$ aerodynamic diameter.

The aerosol mass concentrations were obtained through gravimetric analysis using an electronic microbalance with $1 \mu \mathrm{g}$ sensitivity (Mettler MT5). The samples were kept under a controlled temperature of $24 \pm 2{ }^{\circ} \mathrm{C}$ and a relative humidity of $55 \pm 3 \%$ for $24 \mathrm{~h}$ prior to weighing. The limit of detection (LOD) for the aerosol mass concentration is approximately $0.6 \mu \mathrm{g} \mathrm{m}^{-3}$, whereas the precision is estimated to be lower than 5\%. Equivalent $\mathrm{BC}$ concentrations in the aerosol fine mode were measured using a reflectance technique (smoke stain reflectometer, diffusion system, model M43D) and calibrated using $\mathrm{BC}$ gravimetric standards. ${ }^{8}$ To determine the water soluble fraction and the elemental concentrations of the aerosol collected on the filters, the samples were divided into two pieces using a stainless steel blade and by splitting the filter into a one-quarter piece and a three-quarter piece.

Ion chromatography was performed using the onequarter filter fraction and after extracting the water soluble ions from the filter with $10 \mathrm{~mL}$ of Milli- $\mathrm{Q}^{\circledR}$ water by ultrasonication for $30 \mathrm{~min}$. Subsequently, it was applied to a two column Dionex Thermo D-5000 ion chromatographer, which allows for the simultaneous determination of cations $\left(\mathrm{NH}_{4}^{+}, \mathrm{Na}^{+}, \mathrm{K}^{+}, \mathrm{Mg}^{+2}\right.$ and $\left.\mathrm{Ca}^{+2}\right)$ and anions $\left(\mathrm{F}^{-}, \mathrm{Cl}, \mathrm{Br}, \mathrm{NO}_{3}{ }^{-}\right.$, $\mathrm{SO}_{4}^{-2}, \mathrm{PO}_{4}^{-3}$, formate, acetate and oxalate) and thus reduces the time for analysis and consumables. The operational conditions are presented in Table S1 (in the Supplementary Information (SI) section).

For the three-quarter filter fraction, elemental concentrations were determined after total chemical dissolution of the filter with high purity nitric acid $\left(\mathrm{HNO}_{3}\right)$ and fluoridric acid (HF) using inductively coupled plasma mass spectrometry (ICP-MS). Filter dissolution was performed by microwave heating in closed Teflon ${ }^{\circledR}$ vessels (CEM Mars 5). After the addition of boric acid to eliminate excess HF, the solution was evaporated to dryness under a vacuum and by microwave heating, and then, the residue was dissolved with $10 \mathrm{~mL}$ of $2 \% \mathrm{HNO}_{3} .{ }^{9}$

Mass spectrometric analysis was performed using two PerkinElmer ICP-MS instruments using a quantitative method that had an external calibration that applied In and $\mathrm{Tl}$ as internal standards. A PerkinElmer Nexion 300D with an Aridus II desolvating nebulizer was used to determine 41 trace elements ( $\mathrm{Li}, \mathrm{Be}, \mathrm{Mg}, \mathrm{Ca}, \mathrm{Sc}, \mathrm{Ti}, \mathrm{V}, \mathrm{Cr}, \mathrm{Mn}, \mathrm{Fe}$, $\mathrm{Co}, \mathrm{Ni}, \mathrm{Cu}, \mathrm{Zn}, \mathrm{Ga}, \mathrm{Ge}, \mathrm{As}$, Se, Rb, Sr, Y, Nb, Mo, Ag, Cd, $\mathrm{Sb}, \mathrm{Cs}, \mathrm{Ba}, \mathrm{La}, \mathrm{Ce}, \mathrm{Nd}, \mathrm{Sm}, \mathrm{Eu}, \mathrm{Dy}, \mathrm{Ho}, \mathrm{Yb}, \mathrm{W}, \mathrm{Pb}, \mathrm{Bi}$, Th and $\mathrm{U}$ ), and the PerkinElmer ELAN 6000 with a cross-flow Ryton nebulizer was used to determine 3 major elements $(\mathrm{Na}, \mathrm{Al}$, and $\mathrm{K})$. The operational conditions are presented in Table $\mathrm{S} 2$ in the SI section.

The use of Aridus II, which incorporates one aspire principal factor analysis (PFA) microconcentric nebulizer with a heated microporous polytetrafluoroethylene (PTFE) tubular membrane desolvator, increases the sensitivity, reduces the achieved detection limit and consumes the sample at a rate of only $100 \mu \mathrm{L} \mathrm{min}^{-1}$ in comparison with the previous results obtained from an ultra-sonic nebulizer with a membrane desolvator (CETAC U-6000AT+). The achieved detection limits are shown in Table S3 in the SI section for all species analyzed.

National Institute of Standards and Technology (NIST) standard reference materials 2783 (air particulate on filter media) and 1648 (urban particulate matter) were used to verify the analytical procedure including sample dissolution and ICP-MS analysis.

The second aerosol sampling system was used to collect fine aerosol for organic and elemental carbon determination. 
After passing through the $\mathrm{PM}_{10}$ inlet, the aerosol passes through a very sharp cyclone inlet that removes particles greater than $2.5 \mu \mathrm{m}$. Both inlets were from BGI Mesalabs. The volatile organic compounds were absorbed in a sunset carbon denuder to avoid measured values higher than the actual values of organic carbon. ${ }^{10}$ The aerosol was then absorbed onto a quartz-fiber filter, which was pre-heated in air to remove any residual carbon contamination.

A thermal/optical method was performed for the determination of organic and elemental carbon (OC/EC) on the quartz-fiber filters using a sunset laboratory carbon aerosol analyzer by NIOSH method 5040. ${ }^{11}$

The data quality was assessed using a variety of techniques. Histograms, normal and lognormal distributions were generated for each variable to validate the data and to remove outliers. For each variable, a stepwise linear regression was performed on the validated data set to analyze outliers that were greater than 3 standard deviations. The variables that could not be significantly predicted by the other variables were not used in the data analysis. As a general rule, it is desirable to have at least five times the number of cases than variables to obtain reliable results of a multivariate model in environmental applications. ${ }^{12}$ To reduce the number of variables included in the analysis, additional criteria were used to exclude variables with high similarity from the analysis, which included variables that had a significant number of missing values and variables that could not be associated with any known air pollution sources. After the data validation, 121-122 cases and 27-30 variables were included in each data set (fine and coarse mode aerosols for each sampling site).

Receptor models were used to identify and evaluate the contribution of the pollutant sources in the fine and coarse particle fractions in the metropolitan area of Rio de Janeiro. ${ }^{13}$ A multivariate statistical approach was applied, including PFA, absolute principal factor analysis (APFA) and hierarchical cluster analysis. ${ }^{14-16}$

Multivariate analysis is a tool that allows the interpretation of a database with many variables by means of a statistical treatment. The methods that use this type of analysis lead to results such as: reduction of the database without compromising the value of information, identification of groups of similar variables, identification of relationships among variables, determination of how variables correlate, knowledge of relationships between variables and prediction of some variables in function of others. Applied to the study of particulate matter in the air, the multivariate analysis allows to identify the sources without necessarily knowing their signatures, allowing to estimate the composition of the same, having only measurements in the receptor.
The PFA aims basically to explain the variance or covariance of an extensive data set. ${ }^{15,16}$ Considering a database constituted by the elemental concentration of (p) elements, called variables, and by (n) samples. The PFA model reduces the database of $(p)$ variables to a smaller number $(\mathrm{k})$ of principal factors that contains as much information as possible in the original database, obtaining a reduced matrix that is easier to interpret.

The principal factors are the new variables that were constituted from the correlation between the original variables. Each factor groups variables that have the highest correlation. Variables that have the same variability in time indicate that they come from the same source, the same formation or transport process. In the PFA the identification of the factors indicates qualitatively the composition of the main sources that contribute to the pollution of the region.

There are some assumptions that need to be verified before a PFA. ${ }^{15}$ It starts from the principle that: measurement errors are randomic and uncorrelated, the variability of concentrations is due to source emission variations and not to uncertainty variations in measurement, the number of samples must be greater than the number of variables.

The APFA quantifies the sources identified by the PFA, that is, determines the percentage of emission per source and the responsibility of each source identified to the total emission of pollutants.

Cluster analysis is a widely applied multivariate technique for interpreting analytical data. The main purpose of this analysis is to identify groups of objects with similar properties within a large data set. Starting from the space of $(\mathrm{N})$ dimensions (number of variables or samples), the distances between all points (objects) of this space are calculated. From there, the objects with smaller distances are grouped. From this group, distances between them are calculated again, forming a second level of grouping, and so, successively, levels are created until one has a last level grouping all the objects. This structure is represented in the form of a dendogram which promotes an easy interpretation of the data.

\section{Results and Discussion}

With regard to the WHO air quality guidelines ${ }^{6}$ for fine particles $\left(\mathrm{PM}_{2.5}\right)$, Table 1 shows that only a few violations were observed. In particular, at Taquara and Barra da Tijuca, which were close to the Olympic Games facilities, the highest daily measured concentrations were 21 and $19 \mu \mathrm{g} \mathrm{m}^{-3}$, respectively. Furthermore, comparing the current results with those obtained ten years ago at Barra da Tijuca, ${ }^{7}$ 
it is possible to conclude that they are statistically equal (95\% degree of confidence). The local environmental authority Instituto Estadual do Ambiente (INEA) has published the results of its air quality monitoring program from 2013-2015, ${ }^{17}$ which includes $\mathrm{PM}_{2.5}$ data at the Barra da Tijuca sampling point; the obtained mean values were 13, 16 and $11 \mu \mathrm{g} \mathrm{m}^{-3}$ in 2013, 2014 and 2015, respectively. Comparing both 2013 results, the INEA automatic station presented results $40 \%$ higher than the gravimetric method adopted during the present work $\left(8 \mu \mathrm{g} \mathrm{m}^{-3}\right)$.

A large number violations of the daily WHO air quality guidelines for $\mathrm{PM}_{10}$ were observed at sampling points Duque de Caxias and Taquara, but only two violations were observed for the two sampling points at Tijuca and Barra da Tijuca (Table 1). However, the annual WHO air quality guidelines for $\mathrm{PM}_{10}$ were exceeded at all four sampling stations. The ratios $\mathrm{PM}_{2.5} / \mathrm{PM}_{10}$ and $\mathrm{PM}_{2.5} / \mathrm{PM}_{2.5-10}$ also show the influence of soil and truck movement on air quality (Table 2).

In the vicinity of the sampling point at Tijuca, no major construction activity was taking place during the June 2012-June 2013 sampling period; therefore, the coarse fraction of the $65 \%$ should be taken as the expected ratio for Rio de Janeiro as it fits within the range observed in a previous study of $62-72 \% .^{7}$ Similarly, for the sampling point at Barra da Tijuca, the main landscape modification began at the end of the sampling period, and the observed impact on the $\mathrm{PM}_{2.5-10}$ fraction was not significant even though higher mean and maximum values were observed when compared to the 2003-2005 results.

On the other hand, due to the intense flow of trucks and soil work as a consequence of the construction activity for the Olympic Games, the coarse fraction $\left(\mathrm{PM}_{2.5-10}\right)$ at Taquara, where an express bus corridor was under construction, constituted up to $82 \%$ of the particulate matter. A similar observation was made close to the sampling point at Duque de Caxias, where coarse PM constituted $76 \%$ due to the construction of a metropolitan arc, which is meant to connect the main roads in the vicinity of Rio de Janeiro and thereby reduce the traffic of heavy trucks throughout the city.

During the present work, the $\mathrm{BC}$ content on the $\mathrm{PM}_{2.5}$ fraction varies between 18\% (Barra da Tijuca) and 35\% (Taquara) (Table 2), whereas the observed values about ten

Table 1. Descriptive statistics and the number of observations higher than the WHO air quality guidelines; the mean values in bold represent an annual mean value higher than the guideline

\begin{tabular}{|c|c|c|c|c|c|c|}
\hline & $\begin{array}{l}\text { All stations / } \\
\left(\mu \mathrm{g} \mathrm{m}^{-3}\right)\end{array}$ & $\begin{array}{c}\text { Duque de Caxias / } \\
\qquad\left(\mu \mathrm{g} \mathrm{m}^{-3}\right)\end{array}$ & $\begin{array}{l}\text { Tijuca / } \\
\left(\mu \mathrm{g} \mathrm{m}^{-3}\right)\end{array}$ & $\begin{array}{l}\text { Taquara / } \\
\left(\mu \mathrm{g} \mathrm{m}^{-3}\right)\end{array}$ & $\begin{array}{l}\text { Barra da Tijuca / } \\
\qquad\left(\mu \mathrm{g} \mathrm{m}^{-3}\right)\end{array}$ & $\begin{array}{c}\text { Barra da Tijuca (2003-2005) / } \\
\qquad\left(\mu \mathrm{g} \mathrm{m}^{-3}\right)\end{array}$ \\
\hline \multicolumn{7}{|l|}{$\mathrm{PM}_{2.5}$} \\
\hline Mean value & 10 & 12 & 10 & 10 & 8 & 8 \\
\hline SD & 4 & 4 & 4 & 3 & 4 & 5 \\
\hline RSD & 42 & 39 & 44 & 30 & 45 & 64 \\
\hline Minimum & 1 & 1 & 2 & 4 & 1 & 0.1 \\
\hline Maximum & 26 & 24 & 26 & 21 & 19 & 26 \\
\hline Values $>25$ & 1 & 0 & 1 & 0 & 0 & 1 \\
\hline $\mathrm{N}$ & 488 & 122 & 122 & 122 & 122 & 80 \\
\hline \multicolumn{7}{|l|}{$\mathrm{PM}_{2.5-10}$} \\
\hline Mean value & 34 & 42 & 18 & 56 & 17 & 14 \\
\hline SD & 26 & 21 & 6 & 34 & 7 & 6 \\
\hline RSD & 78 & 51 & 35 & 61 & 39 & 40 \\
\hline Minimum & 5 & 8 & 5 & 12 & 7 & 6 \\
\hline Maximum & 201 & 140 & 33 & 201 & 39 & 30 \\
\hline \multicolumn{7}{|l|}{$\mathrm{PM}_{10}$} \\
\hline Mean value & 43 & 54 & 29 & 66 & 25 & 22 \\
\hline SD & 28 & 23 & 9.7 & 35 & 10 & 9.5 \\
\hline RSD & 64 & 43 & 34 & 53 & 40 & 43 \\
\hline Minimum & 5 & 15 & 10 & 16 & 5 & 8.2 \\
\hline Maximum & 214 & 153 & 52 & 214 & 53 & 53 \\
\hline Values $>50$ & 142 & 61 & 2 & 77 & 2 & 1 \\
\hline
\end{tabular}

SD: standard deviation; RSD: relative standard deviation. 
Table 2. Observed fine to coarse particle ratio, fine and coarse particle to $\mathrm{PM}_{10}$ ratio and black carbon to fine particle ratio

\begin{tabular}{|c|c|c|c|c|}
\hline Sampling site & $\mathrm{PM}_{2.5} / \mathrm{PM}_{2.5-10}$ & $\mathrm{PM}_{2.5} / \mathrm{PM}_{10}$ & $\mathrm{PM}_{2.5-10} / \mathrm{PM}_{10}$ & $\mathrm{BC} / \mathrm{PM}_{2 .}$ \\
\hline Duque de Caxias & 0.33 & 0.24 & 0.76 & 0.28 \\
\hline Tijuca & 0.57 & 0.35 & 0.65 & 0.22 \\
\hline Taquara & 0.23 & 0.18 & 0.82 & 0.34 \\
\hline Barra da Tijuca & 0.45 & 0.30 & 0.70 & 0.18 \\
\hline
\end{tabular}

PM: particulate matter; BC: black carbon.

years earlier ${ }^{7}$ ranged from 18 to $31 \%$ and, therefore, were close to the observations reported in the present study. At Barra da Tijuca, the relative contribution of $\mathrm{BC}$ to the fine mode of $18 \%$ from the current study $18 \%$ remains consistent with the previous findings of $21 \%{ }^{7}$

At the sampling points of Duque de Caxias and Tijuca, there was an automatic air quality station that determined $\mathrm{PM}_{10}$ by applying a beta attenuation monitor, which allowed a comparison between the gravimetric results obtained from the present work and the $24 \mathrm{~h}$ mean values from these monitors (Figures $2 \mathrm{a}$ and $2 \mathrm{~b}$ ). A good correlation was observed between both methods for the two stations; however, for the Tijuca stations, the beta attenuation monitor presented systematic values that were $30 \%$ lower than the gravimetric results, which indicated the necessity for an improvement in the calibration of the monitor.

The correlations between the $\mathrm{PM}_{2.5}$ mass concentration, elementary carbon (EC), organic carbon (OC) and BC were tested. No significant correlation among these parameters was observed at the Duque de Caxias and Taquara sampling points, which may be due to the existence of relevant sources other than the vehicles, such as industries, at these sampling points. On the other hand, correlations were statistically significant for $\mathrm{PM}_{2.5}$ and $\mathrm{BC}, \mathrm{PM}_{2.5}$ and $\mathrm{OC}$, and $\mathrm{BC}$ and $\mathrm{EC}$ at the Tijuca and Barra da Tijuca sampling points.

Tables S4 and S5 in the SI section show the number of samples, the mean concentration and the standard deviation of the variables observed in the fine and coarse particle fractions for each sampling site. Observations showed that elements associated with sea-spray, such as $\mathrm{Na}, \mathrm{Mg}$ and $\mathrm{Cl}$, and elements associated with soil dust, such as $\mathrm{Al}$ and $\mathrm{Fe}$, are mainly present in the coarse mode aerosol fraction. On the other hand, volatile elements, such as $\mathrm{As}, \mathrm{Cd}, \mathrm{Sb}$ and $\mathrm{Pb}$, and secondary aerosol components, such as $\mathrm{NH}_{4}{ }^{+}$, non-seawater sulfate and nitrate, predominantly occur in the fine mode. Elevated $\mathrm{Pb}$ and $\mathrm{Zn}$ concentrations in both fractions were observed at the Duque de Caxias sampling point and reached up to $340 \mathrm{ng} \mathrm{m}^{-3}$ for $\mathrm{PM}_{10}$, which was lower than the $\mathrm{WHO} \mathrm{PM}_{10}$ reference value of $500 \mathrm{ng} \mathrm{m}^{-3}$ for lead. A strong association was found between both elements $\left(\mathrm{R}^{2}=0.686, \mathrm{~N}=118, \mathrm{~F}=257\right)$, and a potential source is
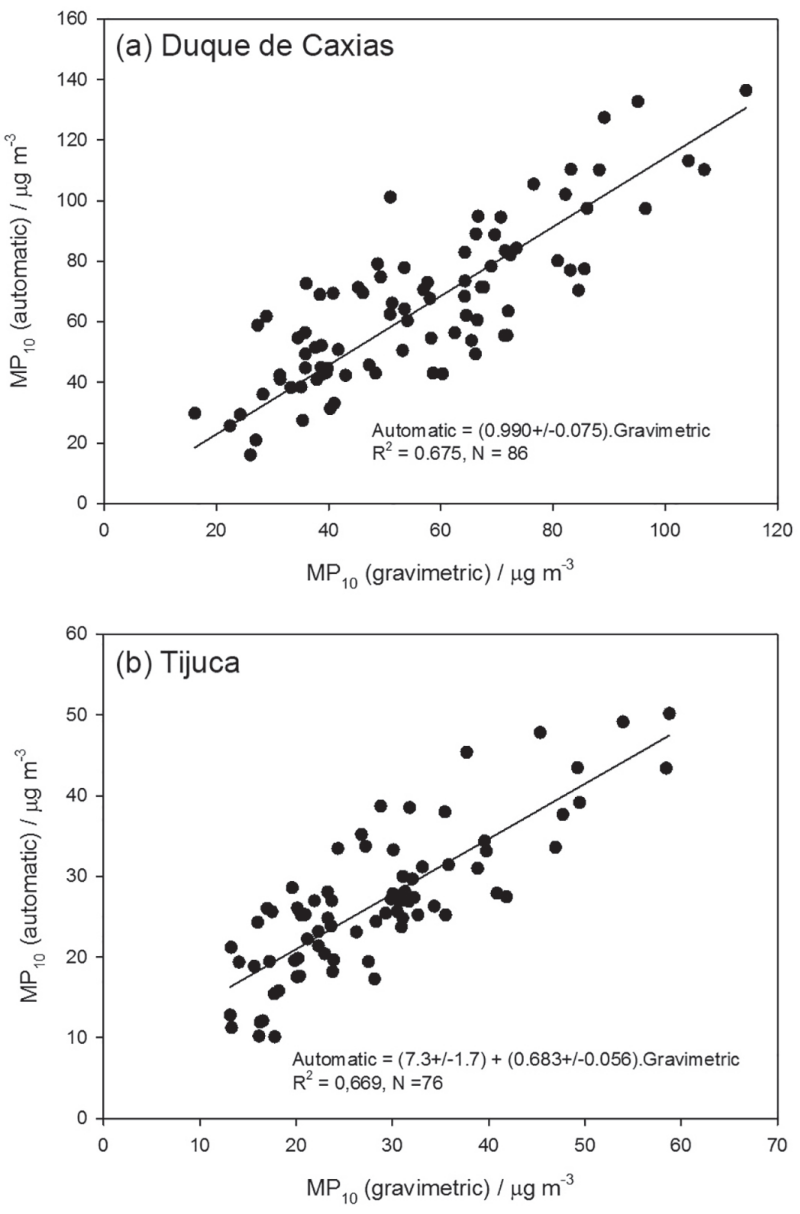

Figure 2. Comparison between $\mathrm{PM}_{10}$ mass results from our gravimetric results and the beta attenuation results obtained for (a) Duque de Caxias and (b) Tijuca.

a zinc plant, which is located $2 \mathrm{~km}$ from the sampling station. The zinc plant produces and purifies zinc oxide and metallic zinc and is the most likely source of lead and zinc in the local area.

Initially, the comparison with the existing literature was restricted to articles involving the city of Rio de Janeiro, long term monitoring, $\mathrm{PM}_{2.5}$ sampling and the determination of total elemental concentration. Only two articles were found, which include our previous work ${ }^{7}$ and the results published by Andrade et al..$^{18}$ The data are shown in Table S6 in the SI section along with the current results. For sampling point 4 (Barra da Tijuca), a large difference 
can be observed between the present work and the work from ten years $\mathrm{ago}^{7}$ for nitrate, which was a factor of two greater than the previous work, whereas sulfate, which is also a component of secondary aerosol related to vehicular traffic, did not exhibit a similar increase. This finding may reflect that larger and heavier vehicular traffic is associated with lower sulfur content in diesel fuel (from S-500 to S-50 during 2012 and S-10 during 2013). In Santiago (Chile), Jhun et al. ${ }^{19}$ observed a $32 \%$ decrease in particulate sulfate as a consequence of the diesel sulfur reduction from 1500 to $50 \mathrm{mg} \mathrm{kg}^{-1}$.

Comparing the results obtained by Andrade et al. ${ }^{18}$ and the current work for the same sampling region (Duque de Caxias), several parameters differed by a factor of two. In general, for the components related to secondary aerosol, such as ammonium, nitrate, and sulfate, as well as mass concentration, the results reported by Andrade et al. ${ }^{18}$ were two times higher than the current results, may be a consequence of the diesel fuel quality improvement. On the other hand, elements such as aluminum, iron and zinc exhibited the opposite tendency in which the present results were more than two times higher than those reported by Andrade et al. ${ }^{18}$ This may be due to the metropolitan arc development during the current sampling period and the existence of this zinc facility about $2 \mathrm{~km}$ away from the actual sampling point.

To permit a better comparison with the existing literature, the search was expanded to other Brazilian and South American large cities (Table S7 in the SI section). It can be observed that the measured values at the Barra da Tijuca sampling point during the present work are lower than those of the other cities. The second lowest values are those related to Recife (Brazil), which is also a city located at the coast and allows a better dispersion of atmospheric pollutants.

The relationship between $\mathrm{PM}_{2.5}$ and the occurrence of rain events is shown in Figure S1 and shows a decrease in $\mathrm{PM}_{2.5}$ concentration after a rain event, although not every reduction corresponded to a rainy day. However, it was not possible to show a clear correlation on a monthly basis between total precipitation and the mean $\mathrm{PM}_{2.5}$ concentration (Figure S2 in the SI section). A similar effect was observed for the $\mathrm{PM}_{2.5-10}$ concentration (Figure $\mathrm{S} 3$ in the SI section) and for some of its main components, such as aluminum, but not for chloride, which is probably due the consistent effect of sea spray throughout the year. On the other hand, Gioda et al.,$^{20}$ based on a 50 year database, showed the existence of a seasonal effect on the $\mathrm{PM}_{10}$ concentration for the Rio de Janeiro metropolitan region with a higher concentration during the winter months, June-August, which also corresponds to the period with lower precipitation.

A very strong correlation between ammonium and sulfate in the $\mathrm{PM}_{2.5}$ fraction was observed at all four sampling points $\left(\mathrm{R}^{2}=0.880-0.950\right)$ with an angular coefficient close to 0.375 and equivalent to that of ammonium sulfate $\left(\left(\mathrm{NH}_{4}\right)_{2} \mathrm{SO}_{4}\right)$, which can range from 0.321 to 0.375 . On the other hand, this correlation was not observed for the $\mathrm{PM}_{2.5-10}$ fraction, which could be explained by a deficiency of ammonium related to secondary sulfate. For example, the medium molar ratio at Duque de Caxias was 0.66 .

The measured carboxylic anions of acetate, formate and oxalate represented 5.6-12\% of the OC present in the $\mathrm{PM}_{2.5}$ fraction. In contrast to the results observed at the two other Brazilian cities, ${ }^{21,22}$ acetate was found to be the main carboxylic acid instead of oxalate, which is consistent with the use of ethanol and gasohol (25\% ethanol) as fuel. It is interesting to note that a small variation was observed among the four sampling points, especially for formate and oxalate. Table 3 shows a comparison between acetate, formate and oxalate concentrations obtained from the present work with those observed by these two authors.

According to Tsai et al., ${ }^{23}$ both oxalate and $\mathrm{K}$ are biomass burning markers, therefore, the correlations of non-seawater $\mathrm{K}$ between oxalate and $\mathrm{OC}$ were tested. For oxalate, the correlation coefficient ranged from 0.591 (Barra da Tijuca) to 0.740 (Tijuca), whereas for OC, it varied from 0.540 (Duque de Caxias) to 0.741 (Tijuca). However, biomass burning is not expected at Tijuca, which represents a highly urbanized region; however, Italian restaurants with wood ovens are quite common in the Tijuca neighborhood. Biomass burning occurs mainly at Barra da

Table 3. Average concentrations of water soluble carboxylic acid anions and comparison with other Brazilian cities

\begin{tabular}{|c|c|c|c|c|}
\hline Sampling site & Formate $/\left(\mathrm{ng} \mathrm{m}^{-3}\right)$ & Acetate / $\left(\mathrm{ng} \mathrm{m}^{-3}\right)$ & Oxalate / $\left(\mathrm{ng} \mathrm{m}^{-3}\right)$ & Reference \\
\hline Duque de Caxias & $61 \pm 32$ & $198 \pm 74$ & $131 \pm 62$ & this work \\
\hline Tijuca & $66 \pm 41$ & $220 \pm 100$ & $135 \pm 58$ & this work \\
\hline Taquara & $65 \pm 43$ & $171 \pm 60$ & $122 \pm 63$ & this work \\
\hline Barra da Tijuca & $59 \pm 34$ & $160 \pm 45$ & $111 \pm 55$ & this work \\
\hline São Paulo, SP & $78 \pm 39$ & $40 \pm 11$ & $250 \pm 94$ & Vasconcellos et al. ${ }^{21}$ \\
\hline Londrina, PR, urban area & 120 & 180 & 470 & Freitas et al..$^{22}$ \\
\hline
\end{tabular}


Tijuca where the correlation coefficients were 0.737 (OC) and 0.591 (oxalate).

The acetate to formate ratio (A/F) can be applied as an indicator of their relative sources, primary or secondary sources: where an $\mathrm{A} / \mathrm{F}>1$ indicates the predominance of primary emission sources while $\mathrm{A} / \mathrm{F}<1$ indicates a relatively higher importance of secondary formation processes..$^{21-24}$ The observed median value was quite similar for the four sampling points, 2.8-3.4, which indicated the predominance of primary emission sources as biogenic emissions, biomass burning and vehicular emissions.

A multivariate statistical approach was applied to study the inter-relationship between the measured compounds and the elements. A combination of PFA, APFA and hierarchical cluster analysis was used to investigate the relationship between the elemental concentrations and their possible sources. PFA was applied individually to each sampling site, and the factor loading matrix was obtained. Only factors with eigenvalues higher than 1 were retained. The statistically significant factor loadings higher than 0.40 were used to interpret the possible aerosol sources associated with each factor retained by the model..$^{25}$

In contrast with the previous work, ${ }^{7}$ when it was possible to identify only three $\mathrm{PM}_{2.5}$ aerosol sources, soil dust, oil combustion and vehicular traffic, due to analytical improvements as lower detection limits and additional parameters as elemental and organic carbon, a range of 4 to 6 factors were identified for the fine particles in the sampling sites, during the present work, and they explain approximately $79-84 \%$ of the data variability for each site. In general, the communality, which expresses the adequacy of the factor model, was high for most of the elements, and this indicated that the identified factors explain most of the data variability of these elements.

A range of 3 to 4 factors were identified for the coarse particles in all of the sampling sites, and they explain $84-87 \%$ of the data variability. Additionally, for the coarse particles, the communality was high for most of the elements.

One of the factors was identified as soil dust based on the presence of elements such as $\mathrm{Al}, \mathrm{Ti}$ and $\mathrm{Ce}$. High factor loadings for $\mathrm{BC}, \mathrm{Ba}$ and $\mathrm{Mn}$ were used to characterize the vehicular traffic factor. The presence of $\mathrm{Ni}$ and $\mathrm{V}$ together with $\mathrm{NH}_{4}{ }^{+}$and $\mathrm{SO}_{4}^{-2}$ ions is an indication of diesel fuel, residual oil combustion sources plus secondary aerosols. The $\mathrm{Na}$ and $\mathrm{Mg}$ association in a factor is an indication that it represents the influence of sea-spray; the $\mathrm{K}$ and $\mathrm{Rb}$ association in a factor is an indication of biomass burning. An industry factor was characterized when elements such as $\mathrm{Pb}, \mathrm{Cu}$, and $\mathrm{Zn}$ are associated.

The distribution in accordance with the higher factor loading of each variable by PFA and by the sampling site is summarized in Figures 3a (for the fine mode aerosol) and $3 \mathrm{~b}$ (for the coarse mode aerosol).

(a)

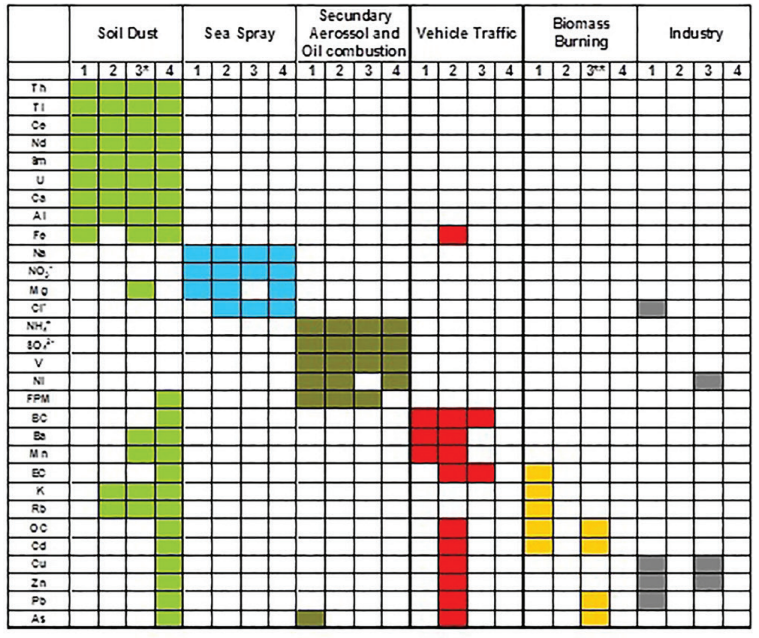

" soil and cement dus

mbioma ss burning and Merck industry!

(b)

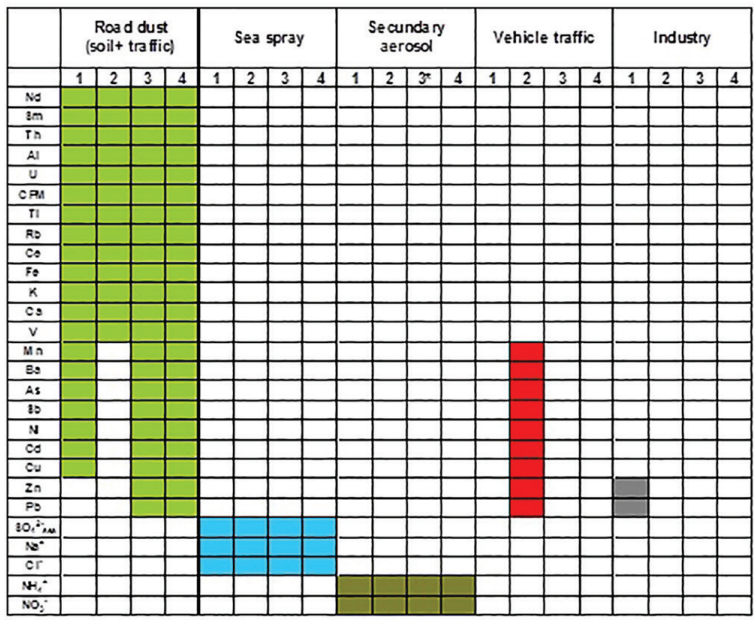

Figure 3. Distribution according to the largest factor loading of each variable by PFA and by each sampling site for the (a) fine mode and (b) coarse mode.

To verify the orthogonality of the identified factors, the factor scores that represent the individual identification of each sample to each factor were added as new variables to each database. A hierarchical cluster analysis was then conducted, and a dendrogram of the clusters was obtained. Each cluster contains one of the factor scores, and a similar pattern of elements was obtained in the PFA, which showed a consistency between the independent multivariate procedures and is shown in Figure S4 in the SI section for the fine and coarse mode aerosol for sampling site 1 .

To perform a quantification of the factor structure, a source apportionment based on APFA was conducted. ${ }^{26}$ The absolute amounts apportioned to the different sources in the fine and coarse mode for each sampling site are shown in Figures $4 a$ and $4 b$, respectively. 
(a) (\%) FPM

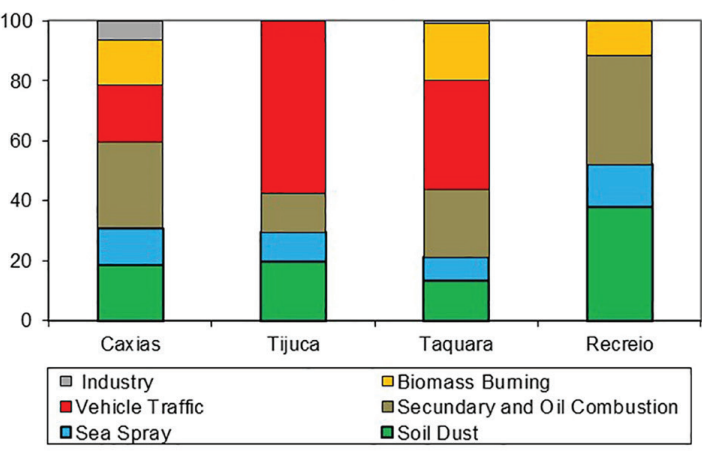

(b)

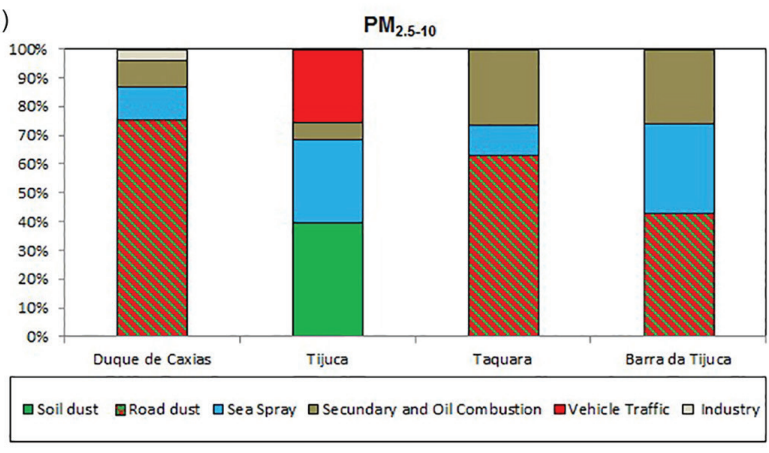

(c)

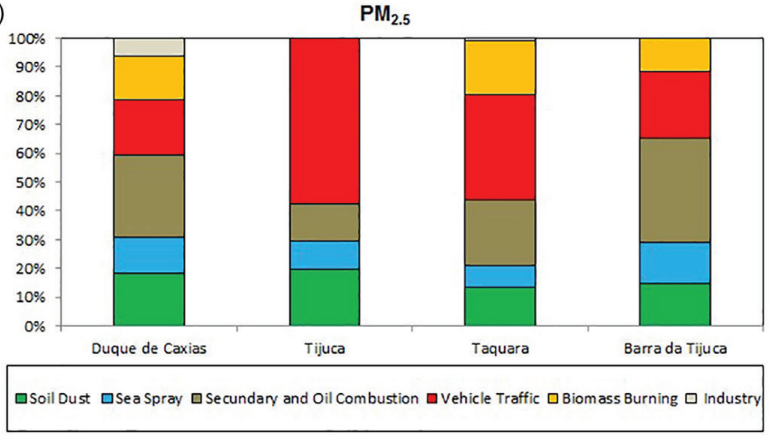

Figure 4. Mass concentration distribution according to the absolute principal factor analysis results for each sampling site for the (a) fine mode (FPM: $\mathrm{PM}_{2.5}$ ), (b) coarse mode (CPM: $\mathrm{PM}_{2.5-10}$ ) and (c) fine mode after the road dust deconvolution.

According to the results of this study, in Duque de Caxias and Taquara, six aerosol sources, including soil dust, secondary/oil combustion, vehicle traffic, sea spray, biomass burning and industry, were observed in the fine mode mass concentration. In Barra da Tijuca, the industry source was not determined, and the soil dust and the vehicular traffic sources were not orthogonal but mixed into one factor. In this case, we named this source road dust. In Tijuca, the burning of biomass and industry sources were not present. Andrade et al., ${ }^{18}$ during their six Brazilian cities work, have obtained five $\mathrm{PM}_{2.5}$ aerosol sources for the Duque de Caxias sampling point, being the main difference, to the present work, the absence of the sea spray source, despite of the proximity to the Guanabara Bay.

To split the road dust factor into soil dust and vehicular traffic factors, the surface soil was sampled around the Barra da Tijuca station, and its elemental composition was determined. Based on the aluminum content of the soil, the aluminum concentration $\left(\mu \mathrm{g} \mathrm{m}^{-3}\right)$ of the road dust factor according to the APFA results and the mass concentration $\left(\mu \mathrm{g} \mathrm{m}^{-3}\right)$ contributed to this factor. This was calculated based on the soil dust concentration subtracted from the road dust concentration, which determined the vehicular traffic contribution $\left(\mu \mathrm{g} \mathrm{m}^{-3}\right)$ to the fine mode at this sampling station. The results are presented in Figure 4c.

Table 4 summarizes the fine mode composition for each sampling station where the vehicular component represents the secondary aerosol and the traffic components together. The vehicular contribution to $\mathrm{PM}_{2.5}$ aerosol ranged from $48 \%$ in Duque de Caxias to $70 \%$ in Tijuca with a mean value of $59 \%$. This suggests a continuous improvement in the public mass transport system where the fuel quality and the vehicular fleet are key actions that could be adopted to improve the existing air quality in the Rio de Janeiro metropolitan region.

Similarly, five sources were responsible for the coarse mode mass concentration, which includes soil dust, vehicle traffic, sea-spray, secondary aerosols and industry. For the Tijuca site only, the contribution of soil could be separated from the contribution of vehicle traffic. For the other sampling sites, both sources appeared together as road dust. The industry source was observed only in Duque de Caxias. This source appeared together with the secondary aerosol factor in the Taquara sampling station but it was absent in the Tijuca and Barra da Tijuca sampling stations, which was consistent with the results of the fine mode.

Figures S5a-d and S6a-d in the SI section show the relative contribution of each identified source to the parameters involved on the APFA and according to each

Table 4. Calculated source contribution for the fine mode particles where the vehicular source represents traffic and the secondary aerosol together

\begin{tabular}{|c|c|c|c|c|c|c|c|}
\hline Sampling site & Soil & Traffic & Secondary & Vehicular & Sea-spray & Biomass & Industry \\
\hline Duque de Caxias & 18.6 & 19.1 & 28.5 & 47.6 & 12.4 & 15.1 & 6.4 \\
\hline Tijuca & 19.8 & 57.5 & 13.0 & 70.5 & 9.7 & - & - \\
\hline Taquara & 13.5 & 36.5 & 22.5 & 59.0 & 7.7 & 18.8 & 1.0 \\
\hline Barra da Tijuca & 15.0 & 23.0 & 36.2 & 59.2 & 14.4 & 11.7 & - \\
\hline
\end{tabular}


sampling station. For $\mathrm{Cu}, \mathrm{Pb}$ and $\mathrm{Zn}$, metals attributed to industrial sources in Duque de Caxias, the industry contribution for the concentration of these elements on the fine mode was of $60 \%$ for $\mathrm{Pb}$ and $40 \%$ for $\mathrm{Cu}$ and $\mathrm{Zn}$, and the remaining fraction was attributed to vehicular traffic and oil combustion. In the other three sampling stations, these elements were almost $100 \%$ related to vehicular traffic and oil combustion. In the coarse mode, the presence of $\mathrm{Cu}$ in Duque de Caxias was attributed mainly to road dust while $30-35 \%$ of $\mathrm{Pb}$ and $\mathrm{Zn}$ were related to industrial sources, and the road dust and the vehicular traffic were the main sources of these metals on the coarse mode.

These relative contributions can also be applied to compare the attributed source profile with the expected one using, e.g., the US EPA SPECIATE data bank. ${ }^{27}$ Figures S7a-d in the SI section show two examples for the fine mode, biomass burning and vehicular traffic, and two for the coarse mode, road dust and sea spray. To more adequately apply a vehicular source profile to the Brazil situation where the vehicles are fueled with ethanol and gasohol (75\% gasoline: $25 \%$ ethanol), particulate samples were collected during car tests performed according to the FTP75 protocol $^{28}$ at Petrobras Vehicular Emission Testing Laboratory, and the obtained profile is shown in Figure S7b in the SI section (Fontes-Leves). In general, the reconstructed source profile fits with the expected one. The sea spray sulfate on sampling point 1, Duque de Caxias, was the main deviation and may be due to its characteristics, a region highly industrialized and with heavy traffic and with a large non-seawater sulfate contribution.

\section{Conclusions}

For all four sampling stations, the annual mean value for $\mathrm{PM}_{10}$ was above the WHO air quality guideline, although frequent violations of the $24 \mathrm{~h}$ guideline were verified for only two of the sites, Duque de Caxias and Taquara. The main reason for the $\mathrm{PM}_{10}$ violations was related to express road construction activity in the vicinity of the two sampling points, which was reflected by a $\mathrm{PM}_{2.5-10}$ contribution of $82 \%$ at the Taquara sampling station. On the other hand, data from the four sampling points met both the annual and $24 \mathrm{~h} \mathrm{WHO} \mathrm{PM}_{2.5}$ air quality guidelines, which indicates that the air pollution due to fine particulates did not present a concern for the 2016 Olympic Games in Rio de Janeiro.

Four to six fine particle sources and three to four course particle sources were identified. The presence of an industrial source was identified only at the Duque de Caxias and Taquara sampling stations, and biomass burning was absent in Tijuca.
The vehicular contribution to the $\mathrm{PM}_{2.5}$ aerosol ranged from $70 \%$ in Tijuca to $48 \%$ in Duque de Caxias with a mean value of $59 \pm 9 \%$. Consequently, the implementation of a more efficient mass transport network, an Olympic Games legacy, and the modernization of the fleet are actions that will have a major impact on the reduction of the $\mathrm{PM}_{2.5}$ concentration.

In Duque de Caxias, the industrial sources were identified as the origin of $60 \%$ of the $\mathrm{Pb}$ on the fine mode and $40 \%$ of $\mathrm{Cu}$ and $\mathrm{Zn}$. On the other hand, this contribution to the coarse mode was of $30-35 \%$ for $\mathrm{Pb}$ and $\mathrm{Zn}$, whereas $\mathrm{Cu}$ was attributed mainly to road dust. Road dust, soil resuspension and vehicular traffic were identified as the sources of these elements on the fine and coarse mode in the other three sampling stations.

\section{Supplementary Information}

Supplementary data are available free of charge at http://jbcs.sbq.org.br as PDF file.

\section{Acknowledgments}

The authors would like to acknowledge Petrobras for the financial support, the Rio de Janeiro State Environmental Agency (INEA) and Rio de Janeiro municipality by allowing us to install our equipment on their sampling stations. The authors would also like to acknowledge two anonymous reviewers for their comments which helped us to improve the submitted manuscript.

\section{References}

1. Li, Y.; Wang, W.; Wang, J.; Zhang, X.; Lin, W.; Yang, Y.; Int. J. Biometeorol. 2011, 55, 547.

2. Wang, W.; Primbs, T.; Tao, S.; Simonich, S. L. M.; Environ. Sci. Technol. 2009, 43, 5314.

3. Wang, T.; Nie, W.; Gao, J.; Xue, L. X.; Gao, X. M.; Wang, X. F.; Qiu, J.; Poon, C. N.; Meinardi, S.; Blake, D.; Wang, S. L.; Ding, A. J.; Chai, F. H.; Zhang, Q. Z.; Wang, W. X.; Atmos. Chem. Phys. 2010, 10, 7603.

4. Streets, D. G.; Fu, J. S.; Jang, C. J.; Hao, J.; He, K.; Tang, X.; Zhang, Y.; Wang, Z.; Li, Z.; Zhang, Q.; Wang, L.; Wang, B.; Yu, C.; Atmos. Environ. 2007, 41, 480.

5. Guo, S.; Hu, M.; Guo, Q.; Zhang, X.; Schauer, J. J.; Zhang, R.; Atmos. Chem. Phys. 2013, 13, 8303.

6. World Health Organization (WHO); WHO Air Quality Guidelines for Particulate Matter, Ozone, Nitrogen Dioxide and Sulfur Dioxide, WHO Press: Geneva, 2006. Available at http://apps.who.int/iris/bitstream/10665/69477/1/WHO_SDE_ PHE_OEH_06.02_eng.pdf, accessed in September 2017. 
7. Godoy, M. L. D. P.; Godoy, J. M.; Roldão, L. A.; Soluri, D. S.; Donagemma, R. A.; Atmos. Environ. 2009, 43, 2366.

8. Castanho, A. D. A.; Artaxo, P.; Atmos. Environ. 2001, 35, 4889.

9. Godoy, M. L. D. P.; Godoy, J. M.; Artaxo, P.; Atmos. Environ. 2005, 39, 5307.

10. United States Environmental Protection Agency (US EPA); Standard Operating Procedure (SOP) for the Analysis of Organic and Elemental Carbon (OC/EC) using the Sunset Laboratory Semi-Continuous Carbon Aerosol Analyzer, version No. 3; Office of Air Quality Planning and Standards, US EPA: North Caroline, USA, 2012.

11. Birch, M. E.; NIOSH Manual of Analytical Methods (NMAM), NIOSH Method 5040; National Institute for Occupational Safety and Health (NIOSH): Atlanta, GA, USA, 2003. Available at https://www.cdc.gov/niosh/docs/2003-154/pdfs/5040.pdf, accessed in September 2017.

12. Hair Jr., J. F.; Anderson, R. E.; Tathan, R. L.; Black, W. C.; Análise Multivariada de Dados, Artmed Editora: Porto Alegre, Brazil, 2005.

13. Hopke, P. K.; An Introduction to Source Receptor Modeling, Gordon and Breach Science Publishers: Amsterdam, 1999.

14. Artaxo, P.; Oyola, P.; Martinez, R.; Nucl. Instrum. Methods Phys. Res., Sect. B 1999, 150, 409.

15. Johnson, R. A.; Wichern, D. W.; Applied Multivariate Statistical Analysis, $4^{\text {th }}$ ed.; Prentice Hall: New Jersey, 1998.

16. Legendre, P.; Legendre, L.; Numerical Ecology: Developments in Environmental Modelling 20, $2^{\text {nd }}$ ed.; Elsevier: New York, 1998.

17. Ventura, L. M. B.; Ramos, M. B.; Fernandes, L. C.; Soares, C. M.; Santos, J. O.; Rev. Ineana 2016, 4, 6.
18. Andrade, M. F.; Miranda, R. M.; Fornaro, A.; Kerr, A.; Oyama, B.; de Andre, P. A.; Saldiva, P.; Air Qual., Atmos. Health 2012, 5,79 .

19. Jhun, I.; Oyola, P.; Moreno, F.; Castillo, M. A.; Koutrakis, P.; J. Air Waste Manage. Assoc. 2013, 63, 161.

20. Gioda, A.; Ventura, L. M. B.; Ramos, M. B.; Silva, M. P. R.; Water, Air, Soil Pollut. 2016, 227, 86.

21. Vasconcellos, P. C.; Souza, D. Z.; Ávila, S. G.; Araújo, M. P.; Naoto, E.; Nascimento, K. H.; Cavalcante, F. S.; dos Santos, M.; Smichowski, P.; Behrentz, E.; Atmos. Environ. 2011, 45, 5770.

22. Freitas, A. M.; Martins, L. D.; Solci, M. C.; J. Braz. Chem. Soc. 2012, 23, 921.

23. Tsai, Y. I.; Sopajaree, K.; Chotruksa, A.; Wu, H.-C.; Kuo, S. C.; Atmos. Environ. 2013, 78, 93.

24. Wang, Y.; Zhuang, G.; Chen, S.; An, Z.; Zheng, A.; Atmos. Res. 2007, 84, 196.

25. dos Santos, D. A. M.; Brito, J. F.; Godoy, J. M.; Artaxo, P.; Atmos. Environ. 2016, 114, 226.

26. Swietlicki, E.; Puri, S.; Hansson, H.-C.; Atmos. Environ. 1996, 30, 2795.

27. United States Environmental Protection Agency (US EPA); Speciate Data Bank; available at https://www.epa.gov/airemissions-modeling/speciate-version-45-through-40, accessed in September 2017.

28. Environmental Protection Agency (EPA), Federal Test Procedure (FTP) 75, available at https://www.dieselnet.com/ standards/cycles/ftp75.php, accessed in September 2017.

Submitted: June 22, 2017

Published online: September 13, 2017 